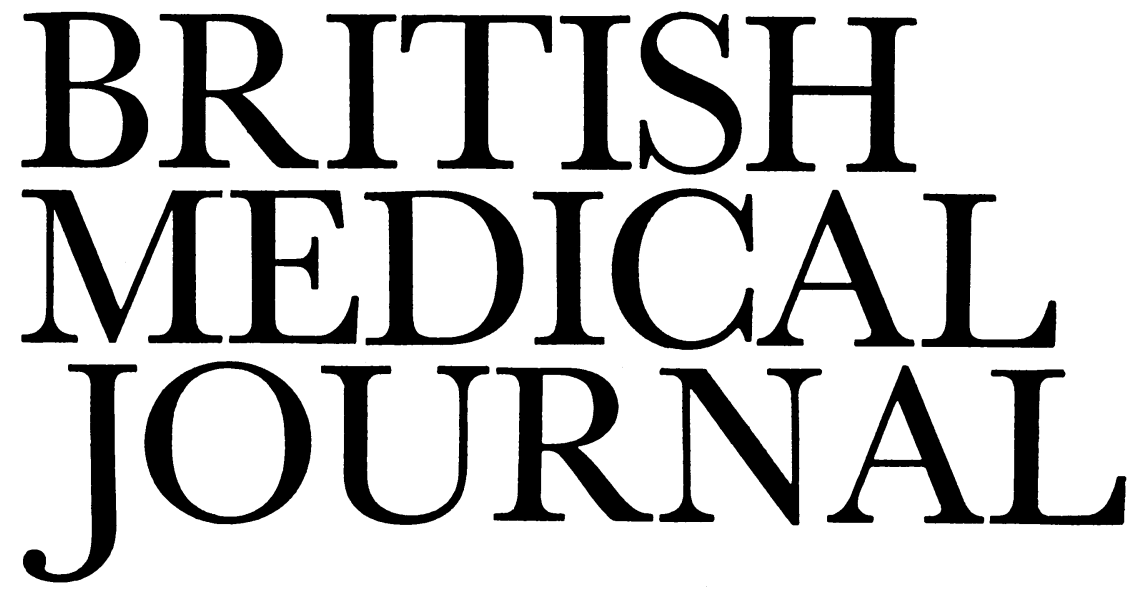

LONDON, SATURDAY 27 JULY 1985

\title{
Short, Black, Baird, Himsworth, and social class differences in fetal and neonatal mortality rates
}

Since the early years of this century a series of official reports has appeared on maternal and child health, the most recent being the follow up report of the Social Services Committee published last year.' Mrs Short's committee welcomed the improvements in perinatal and neonatal mortality that had occurred since the publication of its earlier report, but like most of its predecessors, the report expressed disappointment and concern that the gradient in fetal and infant mortality rates with respect to social class remained as steep as ever ${ }^{2}$ - a matter to which the Working Group on Inequalities in Health chaired by Sir Douglas Black had drawn attention four years previously. ${ }^{3}$ How, then, should we interpret and act on this apparently persistent inequality in life chances? Indeed, as mortality risks continue to fall within each of the individual social classes, should we be concerned about these inequalities at all?

Social classes in Britain are derived from a classification of men's occupations. We still await the development of a satisfactory classification of women's occupations-which might be of considerable relevance to our understanding of variations in fetal and infant mortality rates. ${ }^{4} \mathrm{Be}$ that as it may, it is the persistence of a gradient in mortality rates across the five social classes based on men's occupations that has prompted repeated expressions of concern.

The persistence of social class differences in fetal and infant mortality is likely to have been influenced by three main factors: changes in the classification and distribution of occupations; selective movement of people between social classes; and persisting differences in the extent to which people of different social classes are exposed to various environmental determinants of mortality risks, including social and medical care.

Firstly, to what extent might the persisting gradient reflect changing features of the occupational classification? The origin of the classification is usually associated with the name of T H C Stevenson, superintendent of statistics at the General Register Office at the beginning of this century. There is some dispute about his reasons for developing the classification, ${ }^{6-8}$ but he maintained that it was intended to reflect differences in both wealth and culture between groups of individuals. ${ }^{9}$ He believed these to be important determinants of mortality risks, a belief that was very reasonable given the evidence which had accumulated during the sanitary revolution that environmental factors were important in this respect.
The fact that dividing the population into occupational groups in the way proposed did, in fact, disclose considerable differences in mortality risks within the community was obviously a vindication of his classification-indeed, it has been suggested that Stevenson manipulated the classification to make absolutely sure that it did generate a smooth gradient in mortality risks across his five social classes. ${ }^{7}$

Nevertheless, over the 60 years since men's occupations were first grouped by Stevenson into five classes large changes have been seen in the range and status of occupations within British society. These changes have been reflected in changes in the way that men's work has been classified by successive Registrars General. The bases on which these changes have been made, however, have rarely been made explicit $^{7}$ and it is impossible to assess the extent to which adjustments in the classification have contributed to the maintenance of social class gradients in fetal and infant mortality rates. One trend that has almost certainly operated to maintain the gradient is the declining proportion of births to women married to men in semiskilled and unskilled work. This trend reflects a decline in both the proportion of men employed in this kind of work and fertility rates among their wives. ${ }^{10}$ Social class $\mathrm{V}$ has, therefore, come to occupy an increasingly extreme position on the social class scale-a development that might be expected to increase the likelihood that the mortality experience of its members would compare unfavourably with that of members of social class I, thus tending to maintain the inequality in mortality risks. An additional complicating factor is that, because of a steady increase in the proportion of births to unmarried mothers, the proportion of all births included in the Registrar General's analyses by social class has been steadily declining."

The second factor likely to influence the persistence of the social class gradient in mortality risks is the selective movement of people between social classes, as a result of differences in personal attributes. People move between social classes in a complex and highly selective way. ${ }^{12}$ So far as the social class gradient in early mortality rates is concerned Illsley has provided data that give an insight into the nature of interclass migration. ${ }^{13}$ Women brought up in social classes I and II who marry into social classes IV and V are, compared with others of their class of origin, of shorter stature; score lower on intelligence quotient test; leave school earlier; enter less prestigious occupations; have poorer physiques; have dietary intakes lower in protein, calcium, and vitamins A, B, 
and $\mathrm{C}$; and have a higher risk of losing their babies during the perinatal period. This selective social drift may, in part, reflect genetic influences. ${ }^{14}{ }^{15}$ There is little direct evidence with which this possibility may be assessed, but Thomson has speculated that differences in the height of women in different social classes may, in addition to reflecting environmental influences, imply some degree of genetic selection. ${ }^{16}$ But whatever the determinants of selective social drift may be the evidence suggests that the phenomenon will tend to produce and maintain social class differences in early mortality rates, although the extent to which the persistence of the social class gradient is attributable to this process is unknown.

Finally, the persistence of the gradient may also reflect persisting differences in the environmental circumstances of members of different social classes, including differential access to effective social and medical care. At their most profound these environmental influences may operate across generations ${ }^{17}{ }^{18}$; but there is also evidence to suggest that they may both operate and be mitigated in the shorter term. The steady reduction in the social class gradient in the postneonatal mortality rate-an index which seems to be particularly sensitive to changes in the quality of the environment-is encouraging evidence that social class gradients in mortality are not necessarily immutable. ${ }^{10} 1119$ Whether or not this trend heralds similar reductions in the social class gradient in stillbirth and neonatal mortality rates in Britain remains to be seen. Certainly the social class gradient in the incidence of low birth weight, ${ }^{10}{ }^{11}$ which mirrors the social class gradient in cigarette consumption during pregnancy, ${ }^{21}$ could be reduced by giving effective support to pregnant women who wish to give up smoking. ${ }^{22}$ More generally, social class differences in access to social and medical care seem to continue despite the National Health Service. ${ }^{2326}$ This continuation of the inverse care law ${ }^{27}$ will, like the other factors mentioned, tend to maintain social class gradients in early mortality rates. ${ }^{27}$

There is no sound basis on which the relative importance of the three factors discussed above can be quantifieda state of affairs that inevitably creates fertile ground for the assertion of opinions which (because of the lack of scope for formal experimentation) are difficult to substantiate. And, in a matter so potentially emotive as social inequities in life chances, both analyses and opinions will tend to reflect the social perspective of the commentator ${ }^{28}$ As Thunhurst has put it, "statistical information is not a value-free instrument which somehow 'speaks for itself'; it is socially constructed. Choice of data scrutinized, interpretation of information produced, and even the technical procedures employed necessarily reflect the ideological perspective of the analyst." 29

It is interesting to contrast the views of two of the distinguished medical scientists who have tried to come to grips with these difficult issues. Sir Harold Himsworth has suggested that, though environmental factors determine the absolute size of social class differences in early mortality rates, they do not account for the relative differences between rates in different social classes. ${ }^{19}$ His opinion is that these relative differences are accounted for by social class differences in the distribution of people who are "differently endowed with certain polygenetically determined attributes which determine their potential ability to deal with environmental factors whose adverse effects on their offspring could be prevented or treated."

Sir Dugald Baird has offered an alternative opinion which places more emphasis on the influence of environmental factors. ${ }^{17}{ }^{18} \mathrm{He}$ believes that women are still paying the price of Britain's early and rapid industrial development, suggesting that early mortality rates will not be minimised until a generation has been reared in an environment which $\stackrel{\infty}{2}$ promotes full expression of the genetic potential of every $c$ individual. To illustrate the possible impact of such an $\cong$ environment Baird points to the disappearance of the social class gradient in the height of schoolchildren in Sweden, ${ }^{30} \mathrm{a} \underset{\oplus}{\mathbb{D}}$ country where regional and class disparities in socioeconomic m conditions have been reduced and regional and class differences in infant and later mortality have either disappeared or $\underset{\overrightarrow{0}}{\overrightarrow{0}}$ become much smaller. ${ }^{31}{ }^{32}$

The practical implications of these contrasting interpretations of the same body of evidence are obviously very different. While emphasising the importance of improvements in the mortality rates within each social class, Sir ® Harold encourages us to accept that social class differences in $\vec{O}$ fetal and infant mortality rates are more or less inevitable. Sir Dugald, on the other hand, suggests that British efforts to improve the environment and pursue the social equity which was achieved in Sweden more than a generation ago should in the long term be reflected in a reduction in the social class gradient in fetal and neonatal mortality rates in Britain.

Investigators such as Sir Harold and Sir Dugald will continue to do their best to make sense of the data. ${ }^{33}$ But it is difficult to foresee a time when it will be possible to adjudicate between competing hypotheses on this problem- 9 atic issue with any confidence. In the mean time, my own ideological perspective-coupled with the encouragement that I derive from the reduced social gradient in postneonatal mortality rates-leads me to ally myself with those who call both for distribution of medical and social care according to need and for improvements in the poor environmental circumstances to which the less well off sections of our population are still exposed. There are, after all, good reasons for members of a caring profession to press for environmental improvements, whether or not they turn out to be followed by reductions in the social class gradient in fetal and neonatal mortality rates.

I am grateful to my colleagues and several other people who have tried to guide me through the "tiger country" of social class differences in mortality rates. In particular, I thank Sir Dugald Baird and Sir Harold Himsworth, Professor Martin Bobrow, Dr John Goldthorpe, Dr Klim McPherson, Dr Colin Pritchard, and Dr Simon Szreter. I am also grateful to Anne Ryan for typing the manuscript.

Director,

IAIN CHALMERS

National Perinatal Epidemiology Unit,

Radcliffe Infirmary,

Oxford 0X2 6HE

1 Social Services Committee. Perinatal and neonatal mortality: follow up. London: HMSO, 1984. (Chairman Mrs Renée Short.)

2 Social Services Committee. Perinatal and neonatal mortality. London: HMSO, 1980. (Chairman Mrs Renée Short.)

3 Department of Health and Social Security. Inequalities in health. London: Department of Health and Social Security, 1980.

4 Macfarlane AJ. Official statistics and women's health and illness. Equal Opportunities Commission Research Bulletin 1980;4:43-77.

Kincaid JC. Social pathology of fetal and infant loss. Br Med f 1965;i: 1057-60.

6 Leete R, Fox J. Registrar General's social classes: origins and uses. Population Trends 1977;8:1-7.

7 Jones IG, Cameron D. Social class analysis-an embarrassment to epidemiology. Community Med ones IG, Cameron D. Social class analysis-an embarrassment to epidemiology. Community Med
1984;6:37-48.

8 Szreter SRS. The genesis of the Registrar-General's social classification of occupations. Br f Sociol 1984;35:522-46. 9 Stevenson THC. Vital statistics of wealth and poverty. Fournal of the Royal Statistical Society

10 Oakley A, Macfarlane JA, Chalmers I. Social class, stress and reproduction. In: Rees AR, Purcell H, eds. Disease and the environment. Chichester: John Wiley and Sons, 1982:11-50.

11 Macfarlane AJ, Mugford M. Birth counts: statistics of pregnancy and childbirth. London: HMSO, 1984

12 Goldthorpe JH. Social mobility and class structure in modern Britain. Oxford: Clarendon Press,

13 Illsley R. Professional or public health? London: Nuffield Provincial Hospitals Trust, 1980.

14 Beardmore JA, Karimi-Booshehri F. ABO genes are differentially distributed in,socio-economic groups in England. Nature 1983;303:522-4.

15 Commentary. Blood group and socio-economic class. Nature 1984;309:395-9. 
16 Thomson AM. Growth, heredity and nutrition. Eugenics Review 1959;51:157-62.

17 Baird D. Environment and reproduction. Br f Obstet Gynaecol 1980;87:1057-67.

18 Baird D. Changing problems and priorities in obstetrics. Br F Obstet Gynaecol 1985;82:115-21

19 Himsworth H. Epidemiology, genetics and sociology. F Biosoc Sci 1984;16:159-76.

21 Rush D, Cassano P. Relationship of cigarette smoking and social class to birth weight and perinata mortality among all births in Britain, 5-11 April 1970. I Epidemiol Community Health 1983;37:249-55

22 Sexton $M$, Hebel JR. A clinical trial of change in maternal smoking and its effect on birth weight. 7AMA 1984;251:911-5.

3 West RR, Lowe CR. Regional variations in need for and provision and use of child health services in England and Wales. BrMed $\mathcal{F}$ 1976;ii: 843-6.

24 Brotherston J. Inequality: is it inevitable? In: Carter $\mathrm{CO}$, Peel J, eds. Equalities and inequalities in Brotherston J. Inequality: is it inevitable? In: Car
health. London: Academic Press, 1976:73-104.

25 Downham MAPS, White EMcC, Moss TR. A study of childhood morbidity in relation to the provision of child health services in Newcastle-upon-Tyne, $1975 \& 1976$. Health Trend 1980;12:96-8

26 Taylor EM, Emery JL. Family and community factors associated with infant deaths that might be preventable. Br Med $\mathcal{J}$ 1983;287:871-4.

27 Hart JT. The inverse care law. Lancet 1971;i:405-12.

28 Gould SJ. The mismeasure of man. Harmondsworth: Pelican Books, 1984.

29 Thunhurst C. Social inequalities in health-the medical empire strikes back. Radical Community Medicine 1984:Sept:35-7.

30 Lindgren G. Height, weight and menarche in Swedish urban school children in relation to indgren G. Height, weight and menarche in Swedish urban schoc
economic and regional differences. Ann Hum Biol 1976;3:501-28.

31 Sjolin S. Infant mortality in Sweden. In: Wallace HM, ed. Health care of mothers and children in national health services. Cambridge, Mass: Ballinger, 1975:229-40

32 Erickson R, Aberg R. Valford i forandring: levnadsvillkor i Sverige 1968-81. Institutet for Social Forskning, 1984.

33 Fox AJ, Goldblatt PO, Jones DR. Social class mortality differentials: artefact, selection or life circumstances. F Epidemiol Community Health 1985;39:1-8.

\section{Thyroxine replacement treatment: clinical judgment or biochemical control?}

Hypothyroidism is well recognised to be associated with hyperlipidaemia and coronary artery atheroma, and the initiation of replacement treatment with thyroxine is known to be hazardous. Even gradual restoration of metabolic rate using doses as small as $25 \mu \mathrm{g}$ daily may result in exacerbation of angina or the development of myocardial ischaemia, infarction, and sudden death. ${ }^{1}$ Indeed, restoring normal thyroid hormone concentrations without causing these cardiovascular complications has been compared with steering a course between Scylla and Charybdis. About two fifths of patients presenting with the combination of hypothyroidism and symptomatic ischaemic heart disease cannot tolerate a full replacement dose of thyroxine, ${ }^{2}$ and it is doubtful if the addition of $\beta$ adrenoceptor antagonists or vasodilators is of great benefit. Thus, rather than persevere with medical treatment, there is a case for considering coronary artery surgery at an early stage so that full replacement treatment may be established with safety. In a small series from the Mayo Clinic the presence of untreated or partially treated hypothyroidism did not adversely affect the results of surgery. ${ }^{3}$

What is the correct dose of thyroxine? Based on the amounts necessary to restore thyroid stimulating hormone concentrations to normal in patients with primary hypothyroidism the average daily requirement is $150 \mu \mathrm{g}$ as a single dose. ${ }^{4}$ Pituitary thyroid stimulating hormone secretion is, however, determined by both serum T3 and T4 through intrapituitary conversion of $\mathrm{T} 4$ to $\mathrm{T} 3$, whereas other tissues depend predominantly on the serum $\mathrm{T} 3$ concentration for intracellular T3. ${ }^{5}$ This raises the possibility that, unlike spontaneously developing hyperthyroidism when serum T3 concentrations are consistently raised, an absent thyroid stimulating hormone response to thyrotrophin releasing hormone may not necessarily imply overtreatment in patients receiving thyroxine when serum $\mathrm{T} 4$ concentrations may be raised in the presence of normal serum T3. Is there any harm in prescribing doses of thyroxine greater than those necessary to suppress secretion of thyroid stimulating hormone? In the past it was common practice to use $300 \mu \mathrm{g}$ or even $400 \mu \mathrm{g}$ thyroxine daily for hypothyroidism, goitre, or thyroid cancer without apparently producing clinical evidence of hyperthyroidism in most patients. Possibly the 5'-deiodinase systems responsible for peripheral conversion of $\mathrm{T} 4$ to $\mathrm{T} 3 \mathrm{are}$ less efficient at raised concentrations of serum $\mathrm{T} 4$, thus tending to maintain normal concentrations of serum T3. ${ }^{6}$ Such a mechanism must be only partially effective, however, otherwise thyrotoxicosis factitia would not exist. (These arguments about the relative safety of supraphysiological doses of thyroxine were relied on by the plaintiff in a recent prolonged libel action to dismiss the importance of raised serum T4 concentrations in patients to whom he had given, among other drugs and a diet, thyroid extract in a dose of $250 \mathrm{mg}$ daily for obesity. ${ }^{7}$ Thyroid extract, however, contains both thyroxine and triiodothyronine and, if taken in sufficient dosage to induce a high concentration of serum T4, it is almost invariably associated with a persistently raised serum T3 concentration and clinical evidence of hyperthyroidism. ${ }^{8}$ )

A more likely explanation for the difference between the dose of thyroxine required to suppress thyroid stimulating hormone and that necessary to produce clinical thyrotoxicosis is that clinical judgment is a crude index of thyroid function. Hyperthyroidism, like hypothyroidism, ${ }^{9}$ is almost certainly a graded disorder, with the patient with obvious severe thyrotoxicosis at one end and at the other the patient considered to have what is unsatisfactorily termed subclinical hyperthyroidism on the basis of abnormal biochemical results in the absence of clinical signs. Minor changes in serum T4 may, however, influence heart rate, urinary sodium excretion, and myocardial contractility. ${ }^{1011}$ Indeed, glutathione S-transferase activities are now known to be raised in patients in whom thyroxine replacement treatment has been associated with raised serum T4, but normal T3, indicating minor hepatocellular damage. ${ }^{12}$ None of these tissue effects will be evident clinically.

The cardiac complications of overt hyperthyroidism such as atrial fibrillation, cardiomyopathy, angina, focal myocarditis, ${ }^{13}$ and sudden death from presumed ventricular fibrillation ${ }^{14}$ are well recognised. What is not known is whether the higher so called replacement doses of thyroxine, which are in excess of those required to suppress secretion of thyroid stimulating hormone, may be important in the pathogenesis of these complications in the absence of overt thyrotoxicosis. Heart disease is common in the middle aged and elderly, and a causal relationship is unlikely to be considered when a patient on thyroxine $300 \mu \mathrm{g}$ daily develops angina or goes into ventricular fibrillation, particularly as the mortality rate is low even in overt hyperthyroidism.

As a council of wisdom rather than of perfection enough thyroxine should be given to maintain a normal concentration of serum free $\mathrm{T} 3,{ }^{15}$ preferably with a detectable but normal serum thyroid stimulating hormone concentration measured by a specific and sensitive immunoradiometric assay, and not to rely on reducing the dose only when serum T4 concentrations are high and associated with clinical features of hyperthyroidism. Current tests of thyroid function are so reliable that if there is a discrepancy between biochemical findings and clinical assessment the results of the tests, if confirmed, should usually determine the appropriate dose of replacement thyroxine.

ANTHONY D ToFT

Senior Lecturer and Honorary Consultant Physician

Royal Infirmary,

Edinburgh EH3 9YW 